\title{
Temperature measurement with thin film sensors during warm forging of steel
}

\author{
M. Plogmeyer ${ }^{1} \cdot$ J. Kruse ${ }^{2} \cdot$ M. Stonis ${ }^{2} \cdot$ N. Paetsch ${ }^{3} \cdot$ B.-A. Behrens ${ }^{2} \cdot$ G. Bräuer ${ }^{1}$
}

Received: 8 December 2020 / Accepted: 10 December 2020/Published online: 24 January 2021

(C) The Author(s) 2021

\begin{abstract}
Warm forged components have better surface properties and higher dimensional accuracy than hot forged components. Diamond-like-carbon (DLC) coatings can be used as wear protection coatings, which are anti-adhesive and extremely hard (up to $3500 \mathrm{HV}$ ), to increase tool service life. In the first funding period of the research project at the IPH - Institut für Integrierte Produktion Hannover gGmbH and the Institute for Surface Technology (IOT) of the Technical University of Braunschweig in cooperation with the Fraunhofer Institute for Surface Engineering and Thin Films (IST), the influence of different coating types and process temperatures on tool wear was investigated. The result is, that DLC coatings can reduce tool wear in some cases significantly, but that their service life is strongly dependent on the temperature. Coating-integrated temperature measurement could not be realised at that point, due to adhesion challenges. During the second funding period, the effect of multilayer DLC coatings on tool wear was investigated. Also, an additional method of the temperature measurement on the engraving surface using thin film sensors was developed in order to correlate the local process temperature and local layer wear. In this work, the development of and the results gathered by the thin film temperature sensors are presented, which enable for more accurate temperature measurements than commonly used thermocouples. Their functionality and durability under high loads were investigated and showed to be promising.
\end{abstract}

\section{State of the Art: Temperature measurements in forming technologies}

To reduce the heat loss of the billet during the forging process and to hold the temperature of the die at a constant level, forging dies are usually (pre-)heated. Knowledge about the billet temperature and its distribution is essential in order to improve the quality of the forging process and therefore the quality of the part itself. Only with information about the temperature of the part before and after forging, the heating strategy and the reduction of die wear are possible, due to possible material flow optimization (Müssig 2002).

M. Plogmeyer

m.plogmeyer@tu-braunschweig.de

1 Institute for Surface Technology (IOT), TU Braunschweig, Bienroder Weg 54E, 38108 Braunschweig, Germany

2 IPH - Institut für Integrierte Produktion Hannover gGmbH (IPH), Hollerithallee 6, 30419 Hannover, Germany

3 Fraunhofer Institute for Surface Engineering and Thin Films (IST), Bienroder Weg 54E, 38108 Braunschweig, Germany
Thermocouples are commonly used to measure the die temperature (Fig. 1a). The disadvantage of this method is that the thermocouple can usually only be installed with a minimum distance from the die surface. As a result, no temperature measurement is possible in the direct contact zone between the billet and the tool. This method of die temperature measurement results in delayed and low-resolution values (Hatamura and Yoneyama 1989) that are only an approximation of the real temperature (Fig. 1b).

One approach to calculate the real die surface temperature is the measurement using the technique shown in Fig. 2. Yoneyama and Tozawa (1990) used two separate thermocouples which were arranged with different, but defined, distance to the forging tool surface. Due to the difference in temperature and the known material properties (heat transfer coefficient and thermal conductivity), the temperature on the surface could be estimated.

As shown above, no direct measurement of the contact area between the part and die is possible with conventional methods. Optical measurement techniques are not discussed since they are not able to measure between billet and part when the die is closed. This paper discusses the potential of thin film sensors during warm forging. 
(a)

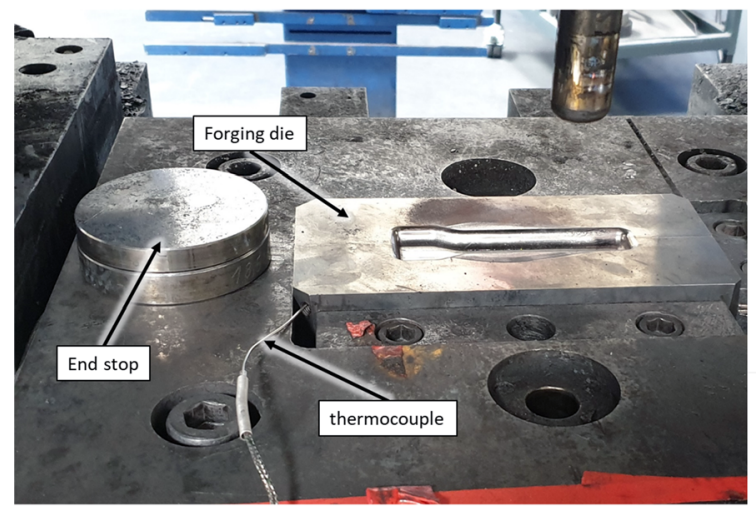

(b)

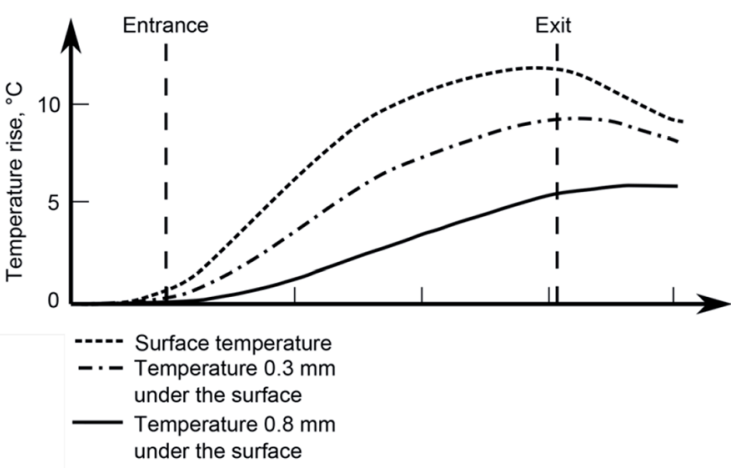

Fig. 1 a Conventional forging die with thermocouple, b Response behaviour of thermocouple depending on surface distance (according to Hatamura and Yoneyama 1989)
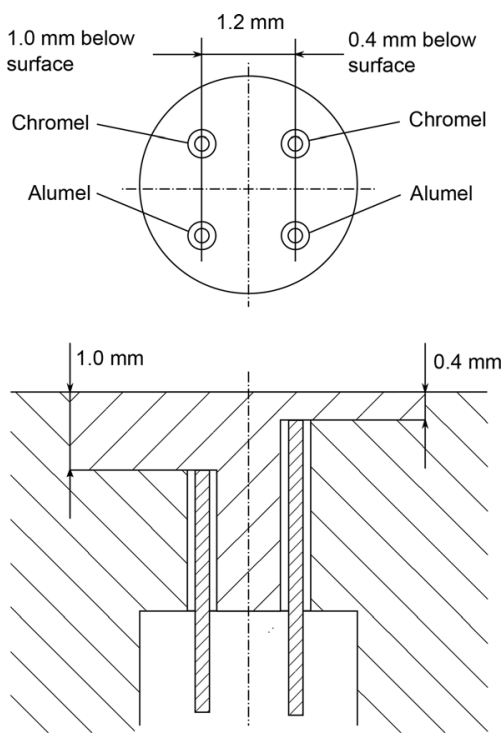

Fig. 2 Approach for the determination of the surface temperatures with the use of two separate thermocouples (according to Yoneyama and Tozawa 1990)

Thin film sensors are often used to measure temperatures on surfaces (Grant et al. 1981; Urban et al. 1990). They are usually made of a metal, alloy or a semiconductor and feature a rapid reaction time due to their small mass combined with high precision. For applications of thin film sensors on tools, the challenge is twofold: on the one hand, an electrical isolation between the sensor and the metal tool as well as the workpiece should be included. On the other hand, the sensor will be subject to mechanical stress and therefore has to be protected against wear. Both can be addressed with a multifunctional layer system, consisting of insulating as well as wear-protective layers, between which a sensor layer is placed (Biehl et al. 2016). Applications range from strip and deep drawing processes to polymer injection moulding. The advantages are, that the sensors can be integrated in existing settings and allow to generate valuable process data at places of high interest. Thin film sensors have also already been tested in even more demanding processes like warm forging. It was discovered that the sensors could only sustain in non-contact areas due to the high pressure in the die contact area (Raedt 2009). Therefore, further investigation of an application in warm forging is necessary to be able to measure the diebillet contact temperatures.

\section{Development of the temperature sensor}

The thin film sensor system is schematically shown in Fig. 3. At first, an insulating aluminium oxide $\left(\mathrm{Al}_{2} \mathrm{O}_{3}\right)$ layer is deposited homogeneously directly on one half of the die. It is deposited in a physical vapor deposition process (PVD) in a thickness of $4.5 \mu \mathrm{m}$. In order to limit the risk of electrical shorts between the sensor and the steel body, the die is polished beforehand, such that a value of $\mathrm{R}_{\mathrm{z}}<0.1 \mu \mathrm{m}$ is achieved.

In the next step a homogenous layer of chromium is deposited in a PVD process with a thickness of $200 \mathrm{~nm}$. It is subsequently structured by a combination of photolithography and wet-chemical etching. Because of the curved surface of the die, flexible masks for the exposure

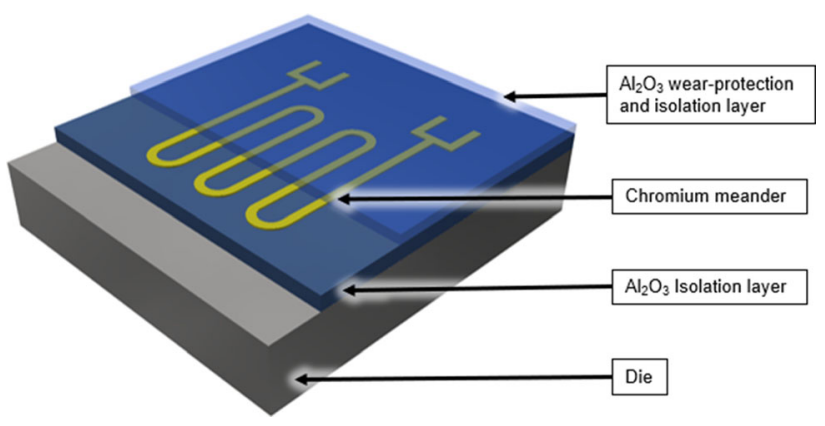

Fig. 3 Schematic of the thin film temperature sensor 
step are fabricated with the sensor design of meander structures and different length of the conducting paths. This allows the sensors to be placed at various positions of interest, while the contact area for wiring is located in an unloaded region (Fig. 4a). In Fig. 4b a microscopic image shows meander structures in detail and how it is possible to structure them on the curved surface. The meander and the conducting paths have a width of $100 \mu \mathrm{m}$.

The sensor structures have to be protected against wear as well as isolated against the metal workpiece with a second $\mathrm{Al}_{2} \mathrm{O}_{3}$ layer which is deposited homogeneously on top with a thickness of $3 \mu \mathrm{m}$. Shielded cables are soldered to each sensor and subsequently protected by epoxy and a heat-resistant sealing paste. Due to failures caused by short circuits to the base body or interruptions in the conducting paths, five of the overall twelve structures could not be used as temperature sensors. Assignments of the sensor denotations are shown in Fig. 5 for the seven functional sensors.

Before measurements can be conducted, each thin film sensor has to be pre-characterized. Therefore, the sensory die is placed into a furnace and the temperature depending resistance changes of the chromium structures are measured by four-terminal sensing. A constant current of $1 \mathrm{~mA}$ is applied through two contacts, while the voltage drop is measured through the other two contacts. The reference temperature is recorded with a Pt100 sensor which is placed directly on the coated surface with heat-conductive paste. Due to the fusion temperature of the solder points, the temperature was limited to about $140{ }^{\circ} \mathrm{C}$ for characterization, while the contacts are not subject to higher temperatures during forging. In Fig. 6, the resulting linear dependency of the resistance from temperature is shown for all sensors on the die. It can be described by:

$R(T)=R_{20}+\alpha_{20} *\left(T-20^{\circ} \mathrm{C}\right)$

with $R_{20}$ as the output resistance at $20{ }^{\circ} \mathrm{C}$ and $\alpha_{20}$ as the temperature coefficient. Assuming linear behaviour for a wider temperature range, the parameters listed in Table 1 for each sensor will be used for estimation of the temperature during forging. An average temperature coefficient of $\alpha_{20}=6,3 * 10^{-4} 1 / \mathrm{K}$ is obtained.

\section{Setup of experimental forging trials}

To test the durability and the sensitivity of the thin film temperature sensors, forging trials were carried out. With all experiments combined, the investigations in the project include over 7000 forging strokes (Schellenberg et al. 2019). Therefore, the geometry of the lower die was kept simple. The upper die only consists of a flat die. Besides the temperature sensor development, the durability of different DLC-layer types is also topic of research in the project. To save costs, only the middle segment of the lower die is coated with the different DLC-coatings and can easily be changed (Fig. 7).

The forging trials were carried out on a Weingarten PSH $4.265 \mathrm{f}$ with $100 \mathrm{~kJ}$ work capacity (Fig. 8a). For the investigations regarding the thin film temperature sensors, a second die was designed, that only consists of two parts. The swappable inlay, used in the previous founding period by Krause et al. (2013) was unnecessary for the current investigations and therefore omitted. Only one half of the lower die was applicated with an array of measurement points, due to its symmetry (Fig. 8b). The final height of the part was determined by the percentage of press energy used and the height of the end stops between press ram and table (Fig. 8c).

The measurement setup during forging consisted of two current sources (Keithley 2601) and a storage oscilloscope (Yokogawa DL750 ScopeCorder) to measure the sensor voltages by four-terminal sensing. Multiple sensors were connected in series to apply a constant current of $1 \mathrm{~mA}$. The acquisition rate was varied between 20 and
Fig. 4 a Placement of the thin film sensor structures on the die, b microscopic image of the meander structures on the curved surface

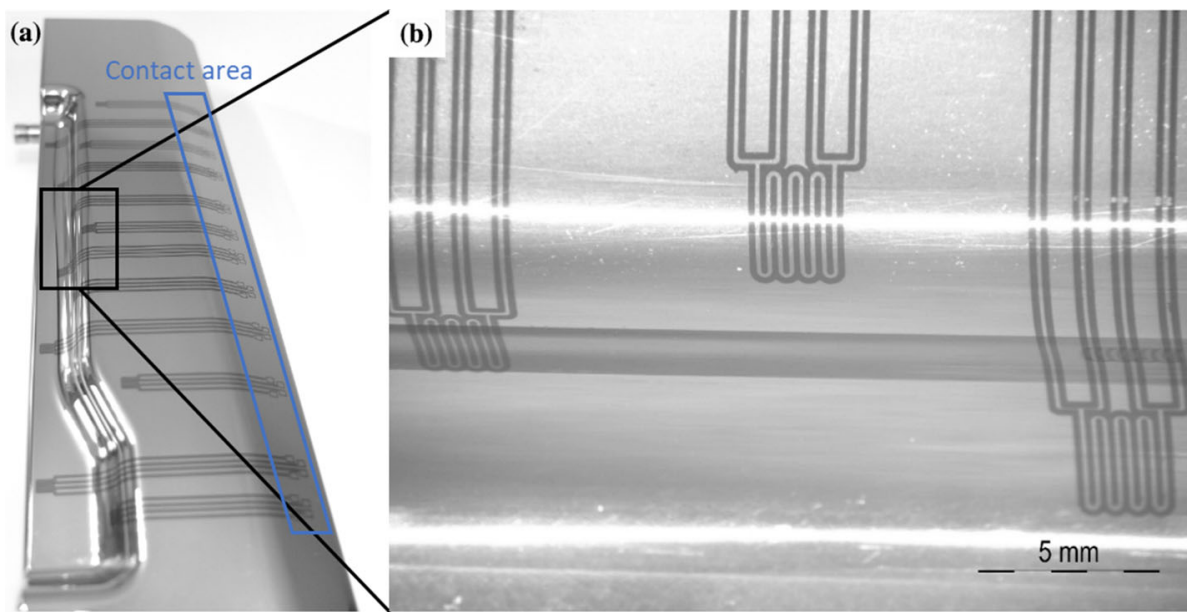


Fig. 5 Sensor denotation of the seven functional thin film sensor structures

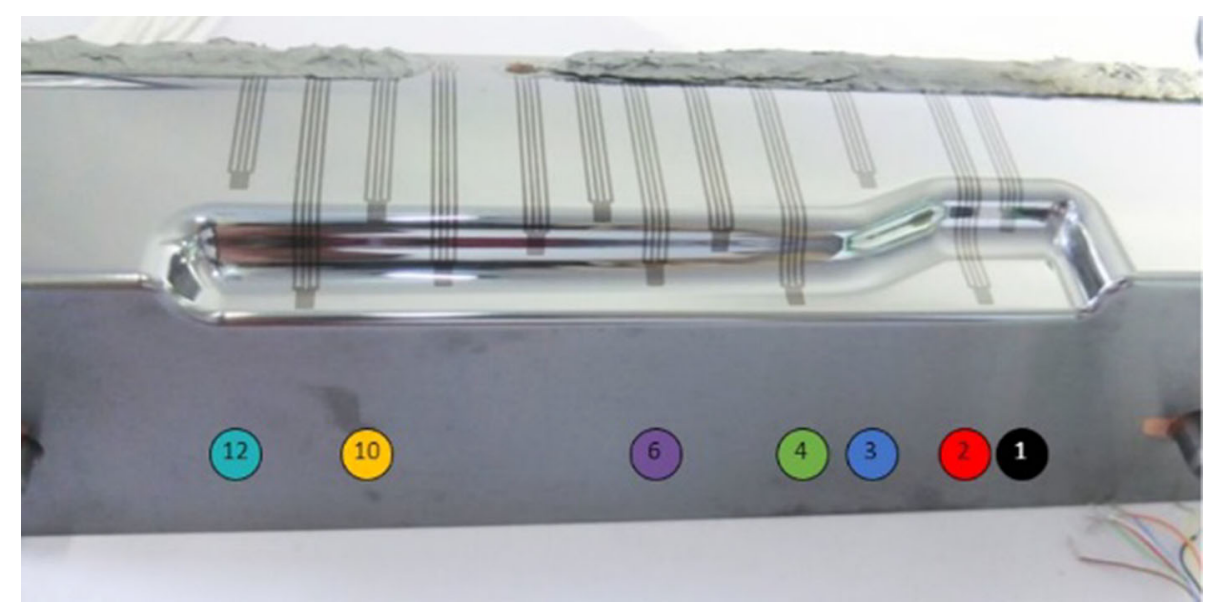

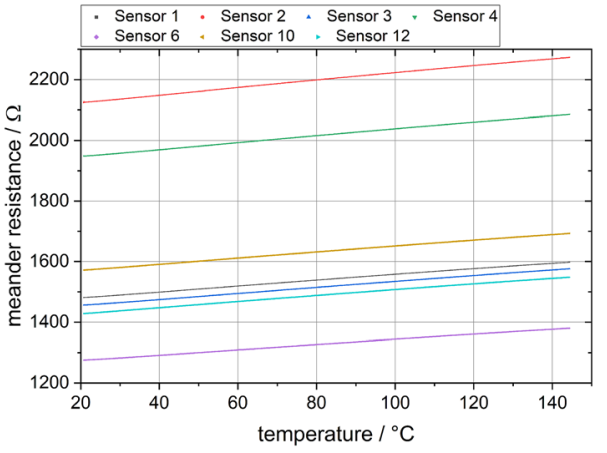

Fig. 6 Electrical resistance of the meander structures in dependence on the temperature

Table 1 Fit parameter of each sensor

\begin{tabular}{lll}
\hline Sensor & $R_{20}$ in $\Omega$ & $\alpha_{20}$ in $10^{-4} 1 / \mathrm{K}$ \\
\hline 1 & 1475 & 6.524 \\
2 & 2121 & 5.558 \\
3 & 1451 & 6.675 \\
4 & 1942 & 5.801 \\
6 & 1270 & 6.765 \\
10 & 1568 & 6.091 \\
12 & 1423 & 6.736 \\
\hline
\end{tabular}

$500 \mathrm{kSample} / \mathrm{s}$. Subsequent data analysis included an estimation of the actual temperature using the linear thermoresistive behaviour of the pre-characterization (Table 1) and filtering with a $1000 \mathrm{~Hz}$ lowpass filter to suppress noise.

The experimental parameters of the die forging process are shown in Table 2. The dies were heated by two heating cartridges with $1 \mathrm{~kW}$ power each. The time-temperature chart (Fig. 9a), recorded with the thin film sensors, shows the heating process before forging.
At first, the die was not heated with full power, to overwatch the stability of the solder points of the thin film temperature sensor during heating up. When the soldering connections turned out functional, the die was heated with full power. It has shown that the sensors give different results for the temperature reading (Fig. 9a). This is related to the positioning of the sensor points on the die surface and their distance to the heating-cartridge (Fig. 9b). The gaps between the temperature curves in Fig. 9a resulted from saving the results. Sensor 2 shows a deviation for a period of time which is explained by an instability of that particular sensor due to imperfect wiring and should be considered when unexpected jumps occur in further measurements.

The billets used with the thin film temperature sensor were heated in a furnace to $750{ }^{\circ} \mathrm{C}$ within $40 \mathrm{~min}$, to ensure homogenous temperate distribution within the billet.

An overview of an exemplary forging process with its separate steps is depicted in Fig. 10, including the recorded temperature profile. The heated die has a surface temperature between 100 and $140{ }^{\circ} \mathrm{C}$ depending on the sensor position (A) before the process. When the $750{ }^{\circ} \mathrm{C}$ hot billet is inserted (B), the temperature rises slowly over time but not abruptly, as no sensor is in direct contact with the billet. Noise caused by the moving press can be clearly seen on each signal (C). The temperature spikes when the stroke happens (D). This section of the measurement will be discussed in more detail in the following chapter. The temperature decreases rapidly, when the press is opening (E), but slowly rises again at most positions as the forged part remains in the die $(\mathrm{F})$. Even sensor 3, which is not in contact with the part, shows a temperature increase, as the heat propagates in the die. An exception is sensor 4, which is dominated by the temperature decrease of the forged part. 

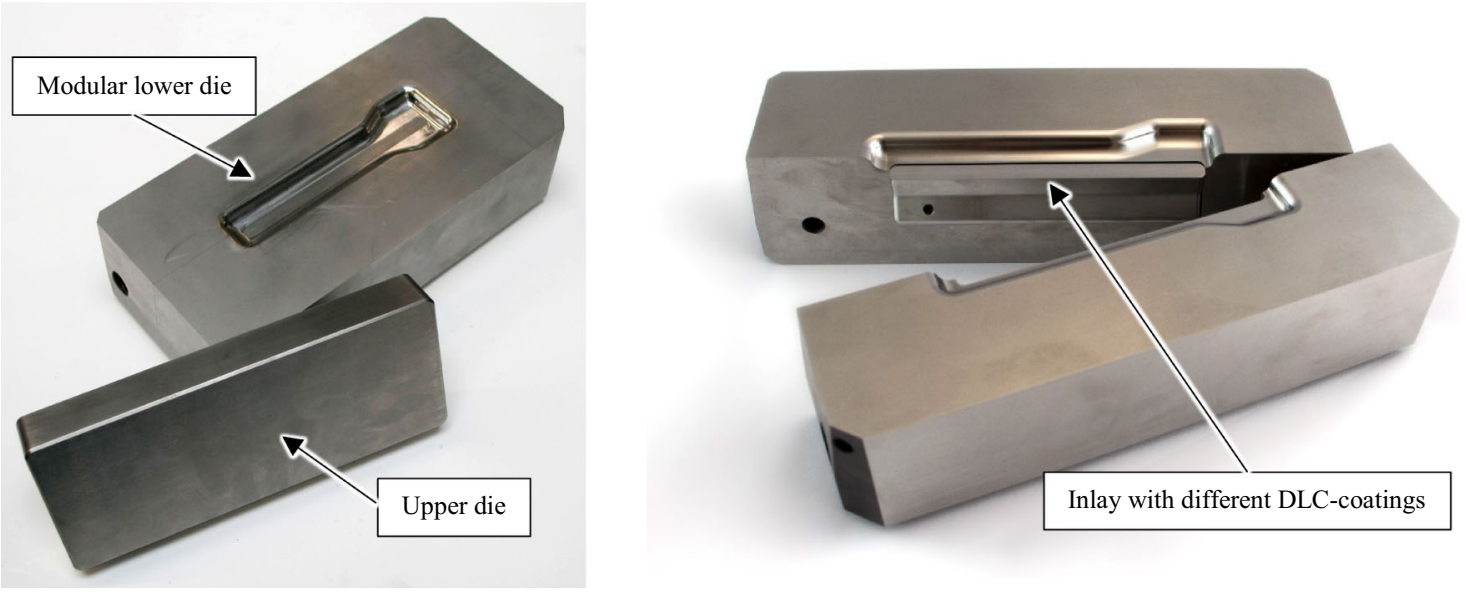

Fig. 7 A lower and upper forging die and position of the inlay

(a)
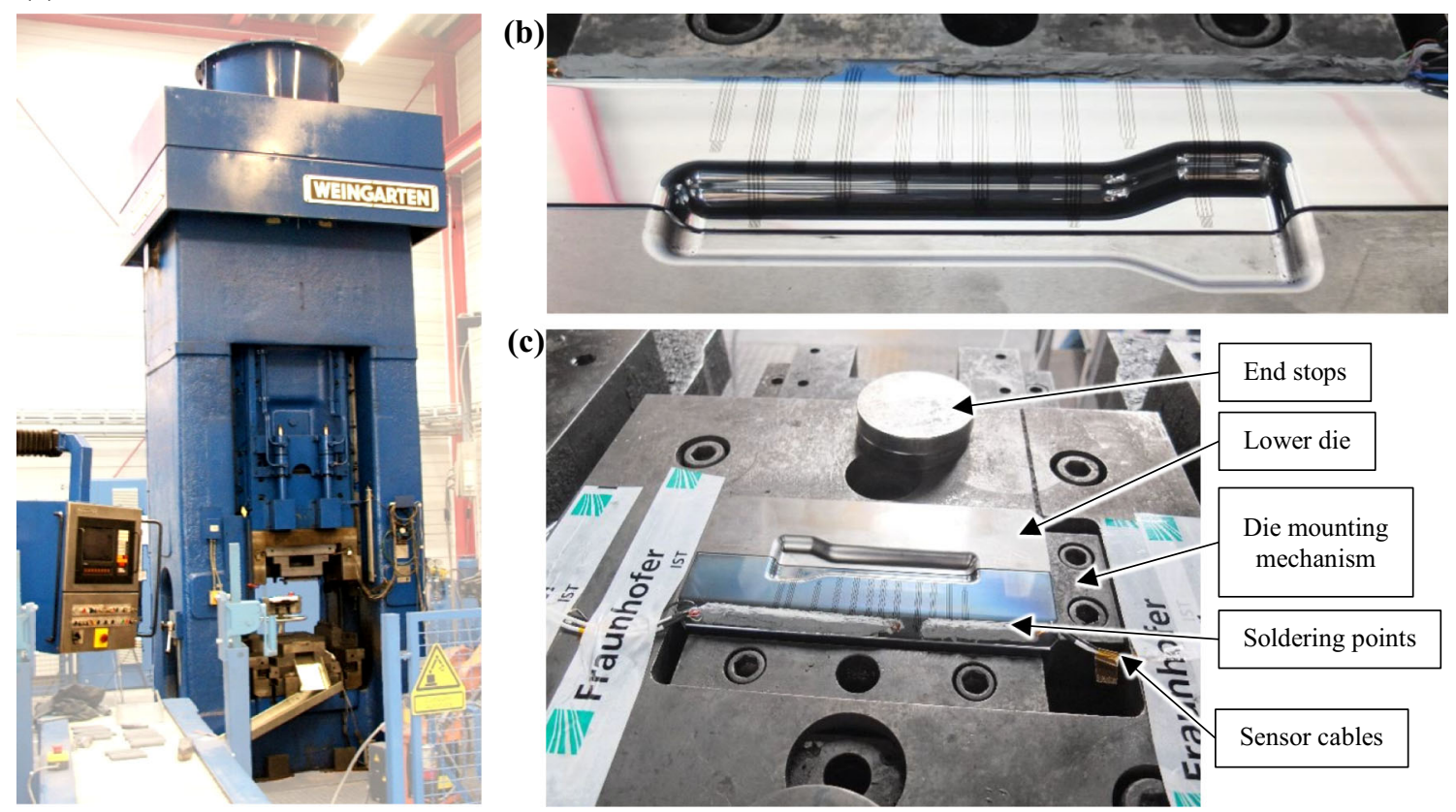

Fig. 8 a Weingarten screw press, $\mathbf{b}$ lower die with temperature sensor, $\mathbf{c}$ mounted die with attached sensor cables

Table 2 Experimental parameters

\begin{tabular}{llllll}
\hline $\begin{array}{l}\text { Targeted die } \\
\text { temperature in }{ }^{\circ} \mathrm{C}\end{array}$ & $\begin{array}{l}\text { Initial billet } \\
\text { dimensions in } \mathrm{mm}\end{array}$ & $\begin{array}{l}\text { Initial billet } \\
\text { temperature in }{ }^{\circ} \mathrm{C}\end{array}$ & $\begin{array}{l}\text { Press energy pre-set in } \\
\text { percent of } 100 \mathrm{~kJ}\end{array}$ & $\begin{array}{l}\text { Resulting press } \\
\text { forces in kN }\end{array}$ & $\begin{array}{l}\text { Forging end stop } \\
\text { height in mm }\end{array}$ \\
\hline min. 120; max. 160 & $\varnothing=20 ; \mathrm{L}=110$ & 750 & $10 ; 28 ; 35$ & $2600-5775$ & $32.5-31.4$ \\
\hline
\end{tabular}

\section{Measurement results}

In the following, the presentation of the results will concentrate on the stroke itself, which takes only a few tenths of a second. At first, measurements were taken with a low energy setting for the forging press. The goal was to test the functionality of the sensors. Therefore, six measurements were taken with $10 \%$ press energy and $32.5 \mathrm{~mm}$ end stop height (Fig. 11). Sensors 1, 3 and 12 do not have contact with the part during the forging process, therefore, they measure only the die temperature and not the part-diecontact temperature. In the case of sensor 3 a slight dip is 
Fig. 9 a Starting phase of lower die heating, b lower die with forged parts
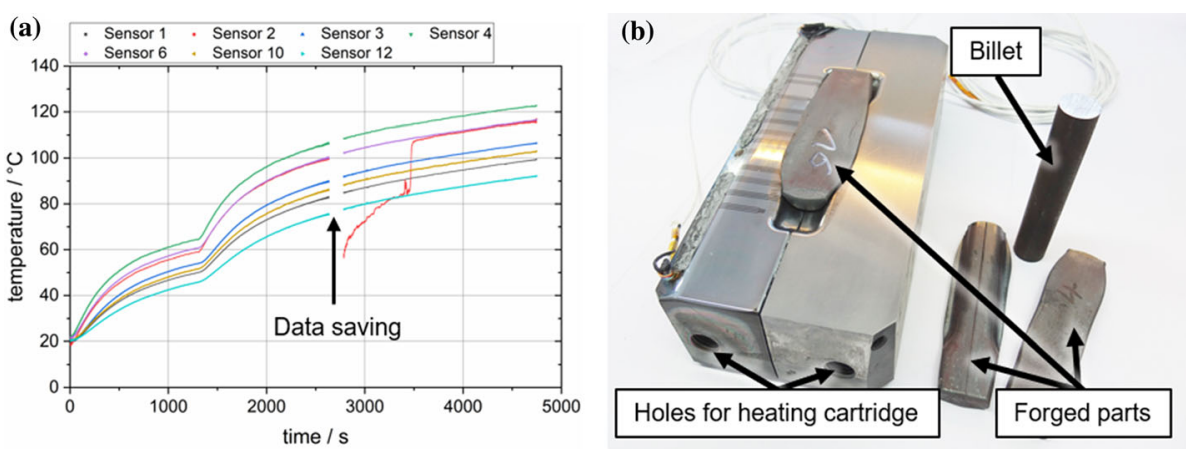

Fig. 10 Exemplary forging steps

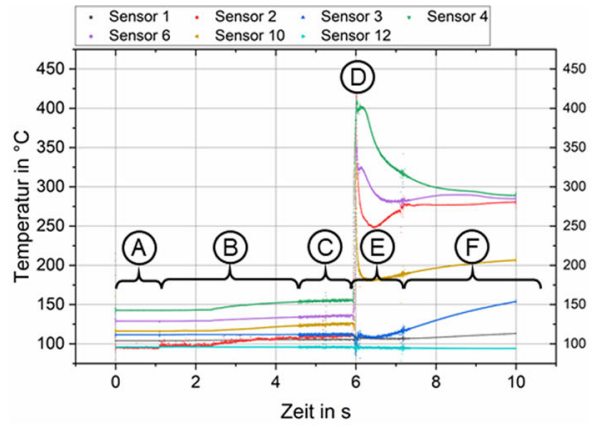

(A) Empty die

(B) Billet insertion

(C) Start press movement

(D) Forging

(E) Opening motion press

(F) Part remains in die until removal
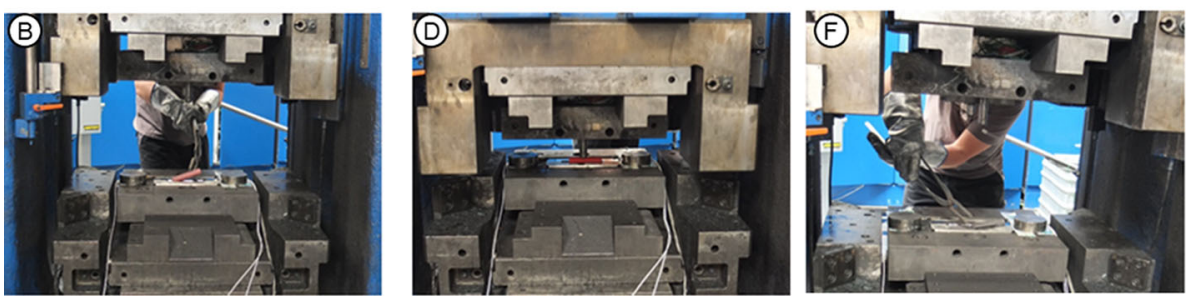

observed. This is not originated by an actual temperature change but rather attributed to be caused by pressure and consequent deformation of the die and thereby leading to a decreased resistance of the chromium sensor which has a negative pressure coefficient. The same can be seen for sensor 10, although the temperature increase overlays this for most of the time. This sensor also perfectly shows the effect of manual insertion and positioning of the billet: While in stroke \#3 a maximum temperature of $\approx 450{ }^{\circ} \mathrm{C}$ is measured, in stroke \#6 there seems to be no contact with the part, only the effect of deformation. Sensors 4 and 6 have a recurring temperature profile for all six strokes because of their central position. Maximum temperatures vary between $400-425{ }^{\circ} \mathrm{C}$ and $350-380{ }^{\circ} \mathrm{C}$, respectively. The only difference between the strokes is when the press is opening up. In some cases, the temperature decreases rapidly by more than $100{ }^{\circ} \mathrm{C}$ in about $0.15 \mathrm{~s}$ (stroke \#6), caused by the heat dissipating into the colder die. In other cases, the temperature drops only $10-20^{\circ} \mathrm{C}$ (stroke \#1), which could be explained by the hot forged part being stuck to the die. For sensor 2, as was the case during heating-up, spontaneous jumps can be observed again.
They are attributed to a defective contact which is why its calculated values should not be considered.

To investigate the effects of die temperature increase due to continuous forging, five parts were forged consecutively (Fig. 12). Sensor 12, which is placed with a distance of more than $10 \mathrm{~mm}$ from the forging area, shows a continuous increase of temperature. All other sensors have a periodic behaviour while the temperature before the stroke increases with every stroke. The maximum temperature during the stroke, which is not dissolved in this diagram, does not increase significantly over the series. Sensor 6 and in some cases sensor 4 as well have a defect leading to a loss of signal. When looking at the data more closely and with a higher time resolution it can be seen that during the strokes, temperatures can be temporarily measured with both sensors though. The reason is suspected to originate from wear of the $\mathrm{Al}_{2} \mathrm{O}_{3}$ layer at the curved areas of the die leading to temporary shorts or disruptions that are temporarily reversed by the stroke. The measurement also reveals at what time the forged part is taken out of the die. At this time, the temperatures of sensor 2, 10 and, 4, 
Fig. 11 Temperature measurements during the first six strokes, taken with press energy of $10 \%$ and $32.5 \mathrm{~mm}$ end stop height
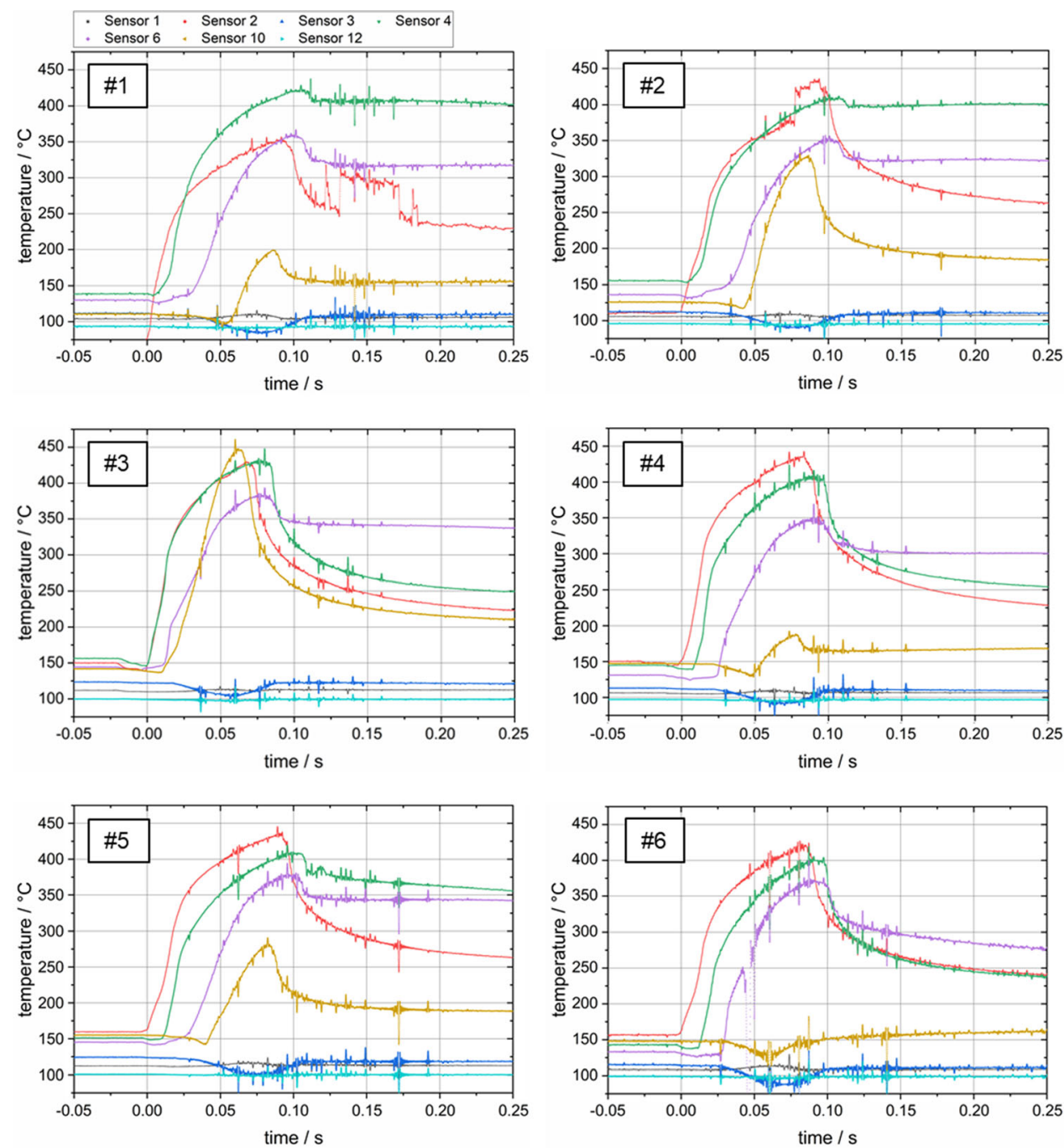

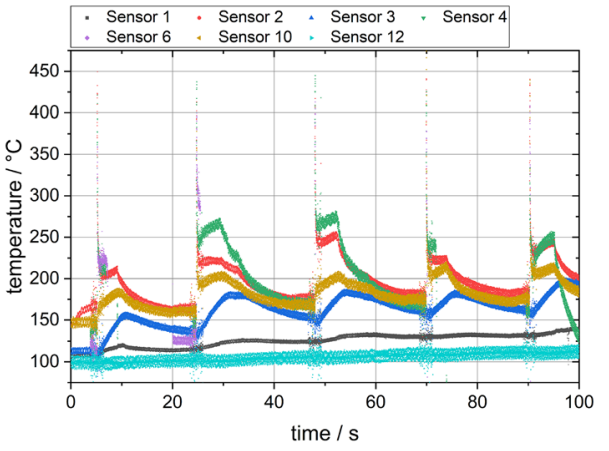

Fig. 12 Temperature measurement during a small series of five strokes (\#7-\#11)

when sensor 4 works as planned, drop abruptly. Sensor 3 shows a slight delay due to its distance.

In the following, the press energy and the height of the mechanical end stops were modified (stroke \#12-\#17). Table 3 shows the changes that were made to the setup with
Table 3 Setups for all strokes

\begin{tabular}{lllll}
\hline Stroke & $\# 1-11$ & $\# 12$ & $\# 13-15$ & $\# 16-17$ \\
\hline Press Energy in \% & 10 & 28 & 28 & 35 \\
End stop height in mm & 32.5 & 32.5 & 31.4 & 31.4 \\
\hline
\end{tabular}

the intention to find out the maximum workload the sensors can measure at.

In Fig. 13 four strokes were chosen representatively to demonstrate the effect of the setup changes. Unfortunately, sensors 4 and 6 showed further damage in stroke \#12 and afterwards were out of order. Sensor 10 experiences the highest temperature of all sensors if in contact with the part. These are even higher than before due to the higher energy and the reduced end stop height with a maximum of about $550{ }^{\circ} \mathrm{C}$. It can also be seen that sensor 3 takes a slightly larger dump with increased energy. After two strokes were performed with the final setup, all sensors, 
Fig. 13 Temperature measurement during strokes with different parameters
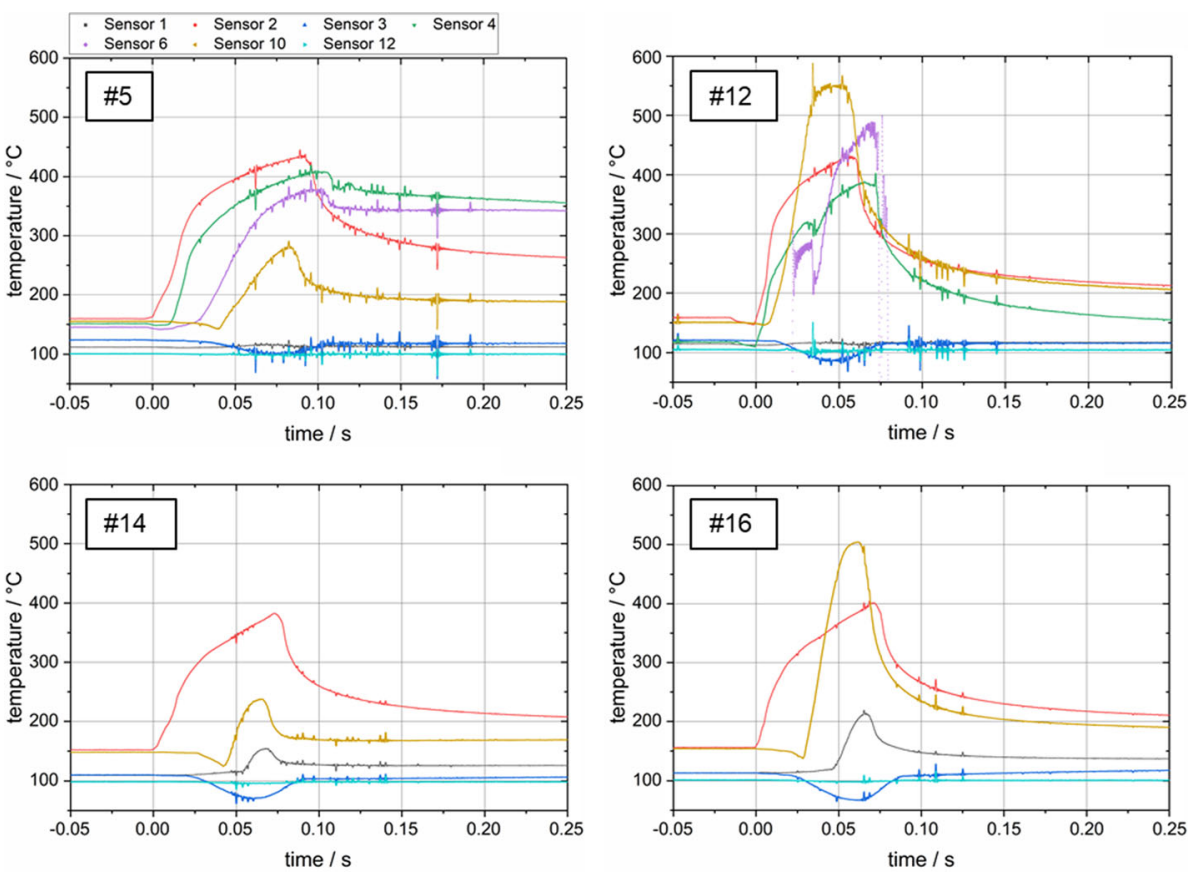

except the two lying on top of the die (3 and 12), were no longer working due to increased wear.

The effect of increased energy and reduced end stop height can be analysed in more detail when looking at the temperature profile of sensor 1 (see Fig. 14). All strokes with changed parameters are depicted in the diagram. While the energy increase from 10 to $28 \%$ has no effect due to the part not coming in contact with the sensor, this is the case when the end stop height is reduced from 32.5 to $31.4 \mathrm{~mm}$. In two out of three strokes performed with these parameters a modest temperature rise can be observed. The deviation of the third stroke is again attributed to manual positioning of the billet. Another energy change to $35 \%$ leads to even higher temperatures of up to $330{ }^{\circ} \mathrm{C}$, indicating that the sensor is at the border up to where the part is forged and therefore being a good indicator for the measure of form filling within the forging die.

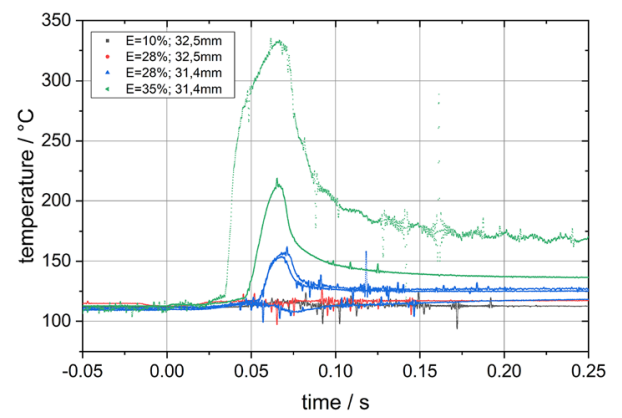

Fig. 14 Temperature measurement of sensor 1 with different parameters

\section{Discussion}

The presented results give a good indication of the actual temperatures on the surface of the die during the warm forging process. Although, all sensors that came into contact with the forged part were no longer working by the end of the forging trials. But this was intended in order to determine the breaking point and potential lifetime of the thin film system. Subsequent analysis of the coated die has shown, that most of the wear occurred on the radius between the upper flat part of the die and the cavity (see Fig. 15). Therefore, most sensor failures can be attributed to the conducting paths being worn out rather than the meander structures. Damage to the sensor was also caused by mechanical removing of the forged parts which stuck to the die, especially for high press energy forging settings.

A couple of aspects should be considered in future experiments to further optimize the temperature measurements.

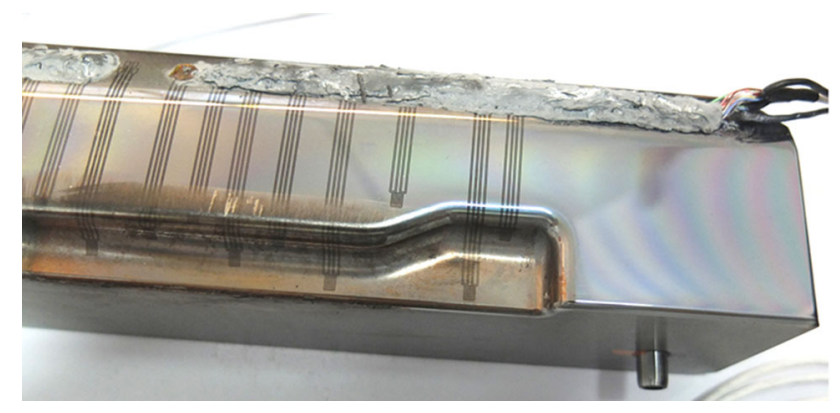

Fig. 15 Lower die with temperature sensors after forging processes 
- The current sensor is coated by a $3 \mu \mathrm{m}$ thick $\mathrm{Al}_{2} \mathrm{O}_{3}$ layer for wear-protection. Unfortunately, this is a low thermal conductivity coating and thereby acting as a thermal barrier. As the process is rather short, the maximum temperature was slightly underestimated. The thermal properties and thickness of this layer have to be considered, for instance in a thermodynamic model or simulation, which was not part of this work.

- As could be seen in the case of sensor 3, pressure or deformation has an effect on the sensor resistance. For a better estimation of the surface temperatures a simulation could take this effect into account leading to slightly increased values.

- Characterization of the sensor was performed only up to $140{ }^{\circ} \mathrm{C}$ due to the low fusion temperature of the solder points. Alternative contacting techniques or verification of measurements by other sensors like pyrometer or thermocouples would allow to verify the measured temperatures.

- The measurements perfectly showed the effect of manual insertion of the billets causing identical forging processes resulting in different temperature profiles for sensors at critical positions. An automated process might increase the comparability between measurements.

\section{Conclusion and outlook}

The goal of this research was to investigate in which range and how sensitive temperatures on the die surface during warm forging can be measured by thin film sensor technology. For this purpose, a warm forging die was equipped with 12 measurement spots on its surface. During forging trials with varying press energy, temperatures were measured during forging operation. The different stages of the forging process, i.e. initial die heating, billet insertion into the die and the forming process followed by the removal of the forged part, can clearly be identified by analysing the time-temperature-graphs. Due to the high sensitivity of the sensors, even slightest temperature differences can be measured, often caused by different positioning of the billet.

Combination of the thin film sensor with an additional wear-protection layer might increase the lifetime of the technology. A remaining uncertainty could be eliminated in future work by the use of thermodynamic models and automated processes. Due to the low latency and high accuracy of the sensor spots, future applications might include positioning control during forging processes, leading to an increased quality of forging parts. Furthermore, inhomogeneous heating strategies for dies and billets could be enabled thanks to a wider understanding of the heat distribution within the forming process.

Funding Open Access funding enabled and organized by Projekt DEAL.. This scientific work has been funded by the Deutsche Forschungsgemeinschaft (DFG, German Research Foundation)-Project Numbers BR 2178/42-1 and BE 1691/220-1.

Data availability Not applicable.

Code availability Not applicable.

\section{Compliance with ethical standards}

Conflict of interest The authors declare that they have no conflict of interest.

Open Access This article is licensed under a Creative Commons Attribution 4.0 International License, which permits use, sharing, adaptation, distribution and reproduction in any medium or format, as long as you give appropriate credit to the original author(s) and the source, provide a link to the Creative Commons licence, and indicate if changes were made. The images or other third party material in this article are included in the article's Creative Commons licence, unless indicated otherwise in a credit line to the material. If material is not included in the article's Creative Commons licence and your intended use is not permitted by statutory regulation or exceeds the permitted use, you will need to obtain permission directly from the copyright holder. To view a copy of this licence, visit http://creativecommons. org/licenses/by/4.0/.

\section{References}

Biehl S, Rumposch C, Paetsch N et al (2016) Multifunctional thin film sensor system as monitoring system in production. Microsyst Technol 22(7):1757-1765. https://doi.org/10.1007/ s00542-016-2831-5

Grant HP, Przybyszewski JS, Claing RG (1981) Turbine blade temperature measurements using thin film temperature sensors. NASA Technical Reports Server. https://ntrs.nasa.gov/archive/ nasa/casi.ntrs.nasa.gov/19810010750.pdf. Accessed 04 Dec 2020

Hatamura Y, Yoneyama T (1989) Measurement of actual stress and temperature on a roll surface during rolling: measurement of temperature and heat flux distribution on the roll surface in cold rolling. JSME Int J. Ser 3, Vibration, control engineering, engineering for industry 32(4):676-680. https://doi.org/10.1299/ jsmec1988.32.113

Krause A, Behrens B-A, Ullmann G, Bräuer G, Weirauch R (2013) Diamond-like-carbon-Verschleißschutzschichten. wt Werkstattstechnik online 103(5):450-455

Müssig B (2002) Temperierung von Schmiedewerkzeugen zur Erhöhung der Bauteilgenauigkeit. Doctoral dissertation. Universität Hannover, Hannover. https://doi.org/10.15488/9621

Raedt H (2009) Verbundvorhaben: Sensorgestützte Werkstoffauslegung und Schichtentwicklung für die Umformtechnik "SenWerkUm", Teilprojekt: Versuchsprogramm zur Anwendung von werkzeugintegrierten Dünnschichtsensoren in der Massivumformung, durchgeführt im Rahmenprogramm "Werkstoffinnovationen für Industrie und Gesellschaft - WING" des Bundesministerium für Bildung und Forschung: Abschlussbericht zum FuE-Projekt. Denklingen/Bayern: Hirschvogel 
Umformtechnik GmbH. https://doi.org/10.2314/GBV: 624821390

Schellenberg D, Kruse J, Langner J, Stonis M, Behrens B-A (2019) Verschleißschutz für Gesenkoberflächen. JOT J für Oberflächentechnik 59(1):40-43. https://doi.org/10.1007/s35144-018-0439-5

Urban G, Jachimowicz A, Kohl F et al (1990) High-resolution thinfilm temperature sensor arrays for medical applications. Sens Actuat A 22(1-3):650-654. https://doi.org/10.1016/09244247(89)80051-2
Yoneyama T, Tozawa Y (1990) Direct measurement of stress and heat between work and tool in metal forming. CIRP Ann 39(1):219-222. https://doi.org/10.1016/S0007-8506(07)61039-7

Publisher's Note Springer Nature remains neutral with regard to jurisdictional claims in published maps and institutional affiliations. 